\title{
Spin $\mathrm{pH}$ and SH probes: enhancing functionality of EPR-based techniques
}

\author{
Valery V. Khramtsov a,b,*, Igor A. Grigor'ev ${ }^{\mathrm{c}}$, David J. Lurie ${ }^{\mathrm{d}}$, Margaret A. Foster ${ }^{\mathrm{d}}$, \\ Jay L. Zweier ${ }^{\text {a }}$ and Periannan Kuppusamy ${ }^{\mathrm{a}}$ \\ ${ }^{a}$ Dorothy M. Davis Heart \& Lung Research Institute, The Ohio State University, Columbus, \\ OH 43210, USA \\ ${ }^{\mathrm{b}}$ Institute of Chemical Kinetics \& Combustion, Novosibirsk 630090, Russia \\ ${ }^{\mathrm{c}}$ Institute of Organic Chemistry, Novosibirsk 630090, Russia \\ ${ }^{\mathrm{d}}$ Department of Biomedical Physics and Bioengineering, University of Aberdeen, Aberdeen, \\ $A B 252 Z D, U K$
}

\begin{abstract}
Along with significant progress in low-frequency electron spin resonance (ESR, also called electron paramagnetic resonance, EPR), other techniques such as Longitudinally-Detected ESR (LODESR), proton electron double-resonance imaging (PEDRI) and field-cycled dynamic nuclear polarization (FC-DNP) have been developed for in vivo applications. However their potential is still far from maximally defined, in part, because of the need for new specific function-directed spin probes. An application of stable nitroxides of imidazoline and imidazolidine types provides unique possibility to measure local values of $\mathrm{pH}$ and thiol content in various biological systems, including in vivo studies. These applications are based on the observation of specific chemical reactions of these nitroxides with protons or thiols, followed by significant changes in their EPR spectra. To increase sensitivity of $\mathrm{pH}$ probes for low-frequency EPR spectroscopy we evaluated two alternative approaches: (i) application of isotopically substituted labels, and (ii) acquisition of EPR spectra at high modulation amplitude. Spatial and spectral-spatial imaging (pH-mapping) using PEDRI and L-band EPR imagers were performed both on phantom samples and in vivo. The applications of the $\mathrm{pH}$ and $\mathrm{SH}$ probes in model systems, biological fluids, and in vivo in living animals are discussed.
\end{abstract}

\section{Introduction}

Significant progress has been made regarding in vivo EPR-based spectroscopy and imaging during the last decade. This includes low-frequency EPR spectroscopy, as well as instrumentation for spatial and spectral-spatial EPR imaging (EPRI) of the radicals [1-8], longitudinally-detected ESR (LODESR) [9], dynamic nuclear polarization (DNP) and proton electron double-resonance imaging (PEDRI) [10,11]. However the potential of these techniques is still far from maximally defined, in part, because of the need for development of new specific function-directed spin probes.

Stable nitroxides of imidazoline and imidazolidine types provide unique possibility to measure noninvasively the local values of $\mathrm{pH}$ and thiol content in various biological systems, including in vivo studies $[8,12]$. These parameters are of principal importance in biochemistry and physiology of living organisms, being significantly compromised in ischemic heart, many tumors, upon local skin treatments or

\footnotetext{
* Corresponding author: Valery V. Khramtsov, Dorothy M. Davis Heart \& Lung Research Institute, 201 HLRI, 473 W 12th Ave, The Ohio State University, Columbus, OH 43210, USA. Tel.: +1 614688 3664; Fax: +1 614293 4799; E-mail: khramtsov-1@medctr.osu.edu.
} 
wound healing, and local areas of infection or inflammation [2,13-17]. Currently there are few methods available for monitoring or imaging $\mathrm{pH}$ and essentially no methods for monitoring or imaging thiols/GSH in living tissues. The most commonly used ${ }^{31} \mathrm{P}-\mathrm{NMR}$ approach for $\mathrm{pH}$ detection has its own limitations, including lack of resolution (about 0.2-0.3 units and even less at lower $\mathrm{pH}$ ), the fact that inorganic phosphate, $\mathrm{Pi}$, concentrations vary with metabolism and ischemia, and its chemical shift depends on ionic strength [18-21]. The possibility of accurate determination of $\mathrm{pH}$ values by EPR is based on early findings that EPR spectral parameters of stable nitroxides of the imidazoline and imidazolidine types depend on the $\mathrm{pH}$ of the medium $[22,23]$. Here we discuss new developments in applications of spin $\mathrm{pH}$ probes using low-frequency EPR spectroscopy and imaging techniques both, in vitro and in vivo.

To our knowledge, there is no direct, noninvasive method for detection of thiols (e.g., GSH) in living tissues. Recently Kuppusamy et al. [2] demonstrated indirect evaluation and imaging of GSH levels in tumors in living animals (mice) by in vivo L-band EPR spectroscopy using a redox-sensitive but thiol-nonspecific spin probe. The application of a SH-specific spin probe might provide even greater specificity and sensitivity to the approach. The thiol-sensitive paramagnetic disulfide biradicals were proposed earlier for thiol detection by X-band EPR spectroscopy [24,25]. Here we evaluated the ability of thiol detection by the disulfide biradicals using L-band EPR spectroscopy and discussed its possible in vivo applications.

\section{Materials and methods}

\subsection{Spin probes}

The structures of imidazoline and imidazolidine probes used in the present work are shown in the Scheme 1 (R1 and R2), Scheme $2(\mathrm{R} 1 *, \mathrm{R} 1 * *$ and $\mathrm{R} 2 *)$ and Scheme $3\left(\mathrm{R}_{1} \mathrm{SSR}_{1}\right.$ and $\left.\mathrm{R}_{2} \mathrm{SSR}_{2}\right)$. The synthesis of the radicals $\mathrm{R} 1$ and $\mathrm{R} 2$ is described in [26], radicals $\mathrm{R} 1 *, \mathrm{R} 1 * *$ and $\mathrm{R} 2 *$ in [27], biradical $\mathrm{R}_{1} \mathrm{SSR}_{1}$ in [24] and biradical $\mathrm{R}_{2} \mathrm{SSR}_{2}$ in [25]. The other reagents were from Sigma.

\subsection{X-band EPR spectroscopy}

EPR spectra were recorded on a Bruker EMX spectrometer in a quartz capillary of $50 \mu 1$ volume. The hyperfine coupling constant, $a_{\mathrm{N}}$, was measured as the distance between the low field and the central line of the triplet and was accurate to $\pm 0.02 \mathrm{G}$. Solutions of the radicals in water or in buffers were titrated with solutions of $\mathrm{HCl}$ or $\mathrm{KOH}$ to the required $\mathrm{pH}$. $\mathrm{pH}$ was measured using an $\mathrm{AB} 15 \mathrm{pH}$ meter (Fisher Scientific).

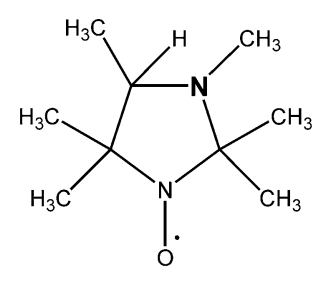

R1 (pK 4.7)<smiles>CC1(C)N=C(N)C(C)(C)N1[O]</smiles>

$\mathrm{R} 2(\mathrm{pK} 6.1)$

Scheme 1. Chemical structures of imidazolidine radical R1 and imidazoline radical R2. The site of protonation, nitrogen atom $\mathrm{N}-3$, is shown in bold. 


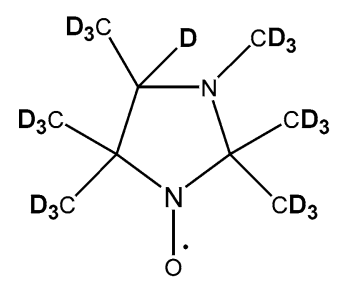

$\mathrm{R} 1^{*}$

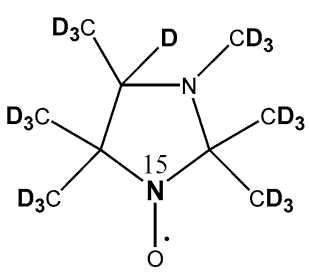

$\mathrm{R} 1 * *$

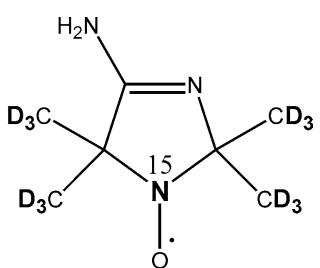

$\mathrm{R} 2 *$

Scheme 2. Chemical structures of isotopically substituted imidazolidine radical R1 and imidazoline radical R2. The site of isotopic substitution for nitrogen ${ }^{15} \mathrm{~N}$ and deuteron, $\mathrm{D}$, are shown in bold.

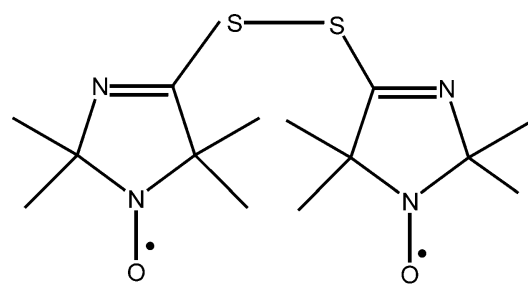

$\mathrm{R}_{1} \mathrm{SSR}_{1}$

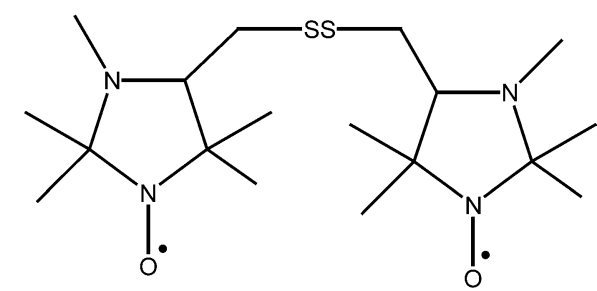

$\mathrm{R}_{2} \mathrm{SSR}_{2}$

Scheme 3. Chemical structures of the imidazoline and imidazolidine biradical disulfides.

\subsection{L-band EPR and EPRI instrumentation}

L-band EPR spectra were measured using a home-built L-band $(1.2 \mathrm{GHz})$ EPR spectrometer described previously [28-30]. Imaging measurements were performed using the L-band EPR imaging instrumentation, consisting of an L-band EPR spectrometer, three sets of water-cooled gradient coils and a personal computer-based data acquisition system. The EPR spectrometer, magnet, and gradient system has been described previously [29-31]. Each set of gradient coils is independently powered with a pair of Hewlett-Packard power supplies (Model 6030A), interfaced to the personal computer via GPIB bus.

\subsection{Projection acquisition and image reconstruction}

The low field peak of the nitroxide triplet spectrum was used for imaging. The imaging experiments were carried out using a variable strength of field gradient with a maximum of $30 \mathrm{G} / \mathrm{cm}$. A total of 64 projections were acquired. The field of view and sweep window were $24 \mathrm{~mm}$ and $10 \mathrm{G}$, respectively. The measured projections were corrected for hyperfine artifacts [30]. A two-stage, filtered-backprojection reconstruction algorithm was used to recover the image [32].

\section{5. $140 \mathrm{GHz}$ EPR measurements}

EPR spectra at $140 \mathrm{GHz}$ were recorded on a homebuilt setup with millimeter-wave bridge designed and built in the Donetsk Physical-Technical Institute of the Ukrainian Academy of Sciences. 


\subsection{FC-PEDRI and FC-DNP measurements}

FC-PEDRI images and FC-DNP spectra were obtained using a home-built imager/spectrometer at the University of Aberdeen [11]. The Overhauser effect is used to detect the free radical probes' unpaired electrons via the measured NMR signal, obtained at $58.7 \mathrm{mT}$ ( $2.5 \mathrm{MHz}$ NMR frequency). For irradiation of the EPR at about $120 \mathrm{MHz}$ the magnetic field is cycled down to approximately $5 \mathrm{mT}$ in the FC-PEDRI experiments, and between 1.5 and $6.5 \mathrm{mT}$ (stepped) in order to record an FC-DNP spectrum (essentially and Overhauser-detected EPR spectrum).

\subsection{Animals}

Adult male Sprague Dawley rats, body weight about $250 \mathrm{~g}$, were used both for in vivo experiments using FC-PEDRI, and for obtaining blood samples for ex vivo L-band experimentation. For the FC-PEDRI studies the animals were fasted prior to being given by oral administration (gavage) $3 \mathrm{ml}$ of $5 \mathrm{mM}$ R1 (Scheme 1) agent. The animals were anesthetized by i.p. injection of $41 \mathrm{mg} / \mathrm{kg} \mathrm{BW}$ ketamine and $20.5 \mathrm{mg} / \mathrm{kg}$ BW xylazine. Animals were killed immediately after the FC-PEDRI studies by pentabarbitone overdose while under anesthesia. Blood samples were obtained from the aorta of the anesthetized rats just before L-band measurements, and biradical $\mathrm{R}_{2} \mathrm{SSR}_{2}(5 \mu \mathrm{l}$ of $1 \mathrm{mM}$ stock solution in $0.1 \mathrm{M}$ PBS, $\mathrm{pH}$ 7.4) was added to $100 \mu \mathrm{l}$ of the blood. All animal procedures carried out at the University of Aberdeen were done so in accordance with local guidelines and under British Home Office project licence no. PPL 60/2300 (M.A.F.).

\section{Results and discussion}

\section{1. pH sensitive nitroxides of the imidazoline and imidazolidine types}

Spin $\mathrm{pH}$ probes of imidazoline and imidazolidine type have spectroscopically distinguishable protonated $\left(\mathrm{RH}^{+}\right)$and unprotonated $(\mathrm{R})$ forms due to the differences in their $g$-factors and hyperfine splittings, $a_{\mathrm{N}}[23,33]$. This is clearly demonstrated by an EPR spectrum measured at $140 \mathrm{GHz}$ and shown in Fig. 1 for the imidazolidine radical R1 (see Scheme 1 for the structure). Note that at high EPR frequency the contribution of the $g$-value in the spectral shift between the forms prevails over hyperfine

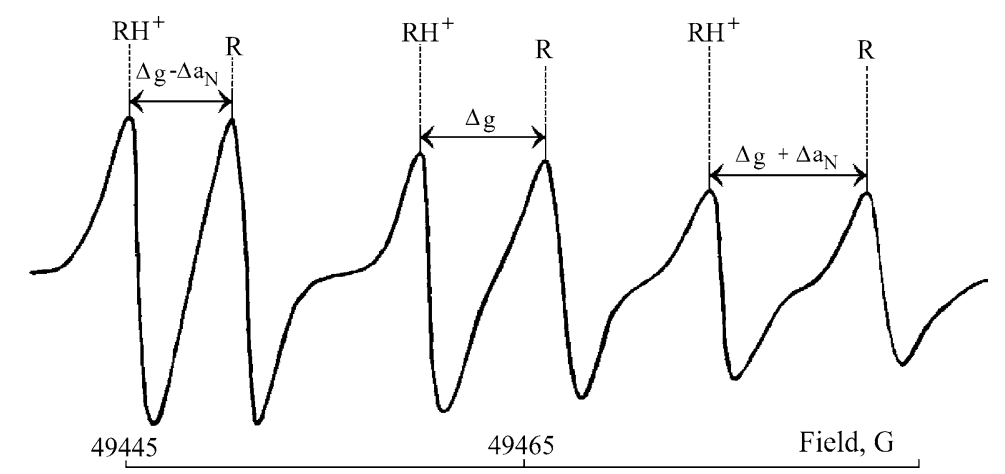

Figure 1. The $140 \mathrm{GHz}$ EPR spectrum of a $0.5 \mathrm{mM}$ aqueous solution of the imidazolidine radical R1 (Scheme 1) at pH 4.7. The dotted lines depict the position of the peaks corresponding protonated, $\mathrm{RH}^{+}$, and neutral, $\mathrm{R}$, forms of the radical. 
splitting difference being equal to $6.7 \mathrm{G}$ and $1.25 \mathrm{G}$, correspondingly, for $\mathrm{R} 1$. The ratio $\left[\mathrm{RH}^{+}\right] /[\mathrm{R}]$ varies with $\mathrm{pH}$ according to the chemical equilibrium of the reaction of proton exchange, namely: $\left[\mathrm{RH}^{+}\right] /[\mathrm{R}]=\left[\mathrm{H}^{+}\right] / K_{\mathrm{a}}$, where $K_{\mathrm{a}}$ is an equilibrium constant of the reaction. This provides an experimental tool for $\mathrm{pH}$ determination using spin $\mathrm{pH}$ probes over the range of about $3 \mathrm{pH}$ units centered on the $\mathrm{pK}$ of the particular radical.

\subsection{Hyperfine splitting of $p H$-sensitive nitroxides as $\mathrm{pH}$ marker}

At X-and L-band EPR frequencies the effect of $g$-factor is decreased resulting in overlapping of the spectral components of the $\mathrm{R}$ and $\mathrm{RH}^{+}$forms (Fig. 2). Therefore, spectral simulation becomes necessary for accurate determination of the $\left[\mathrm{RH}^{+}\right] /[\mathrm{R}]$ ratio. Fortunately, at X-band $(9.9 \mathrm{GHz})$ two convenient experimental parameters might be used as markers for $\mathrm{pH}$ determination, namely: (i) the ratio of the peak intensities of partly resolved high-field lines of the triplets, depicted as $\mathrm{RH}^{+}$and $\mathrm{R}$ in Fig. 2a, and (ii) splitting between low- and central-field components, normally referred as hyperfine splitting, $a_{\mathrm{N}}$.

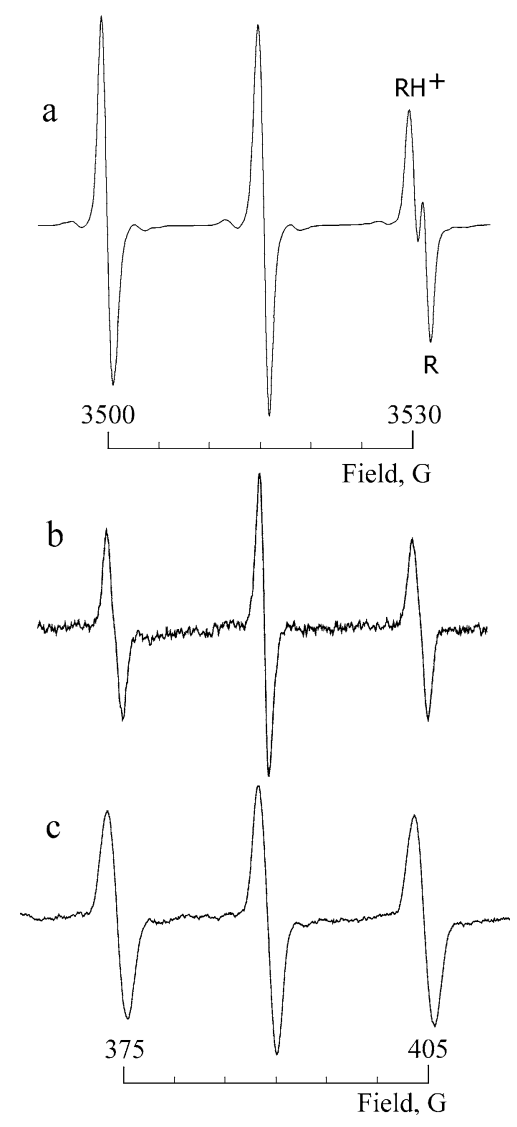

Figure 2. EPR spectra of aqueous solutions of $0.5 \mathrm{mM}$ imidazoline nitroxide, R2, at pH 6.1 measured at X-band (a) and L-band (b), (c). The spectrum (c) was detected at significantly higher modulation amplitude, $2 \mathrm{G}$, compared with $0.5 \mathrm{G}$ modulation for the spectra (a) and (b). Note that shifts between $\mathrm{RH}^{+}$and $\mathrm{R}$ forms of the radical for low- and central-field components of the X-band spectrum (a) practically coincide (corresponding apparent shifts $\left(\Delta a_{\mathrm{N}}-\Delta g\right) \approx \Delta g \approx 0.4 \mathrm{G}$ ) and are significantly lower than EPR linewidths of these forms $\left(\Delta \mathrm{Hpp}\left(\mathrm{RH}^{+}\right) \approx \Delta \mathrm{Hpp}(\mathrm{R}) \approx 0.8 \mathrm{G}\right)$. Spectrum (c) shows improvement of the signal-to-noise ratio compared with spectrum (b) by about 2.1 times. 


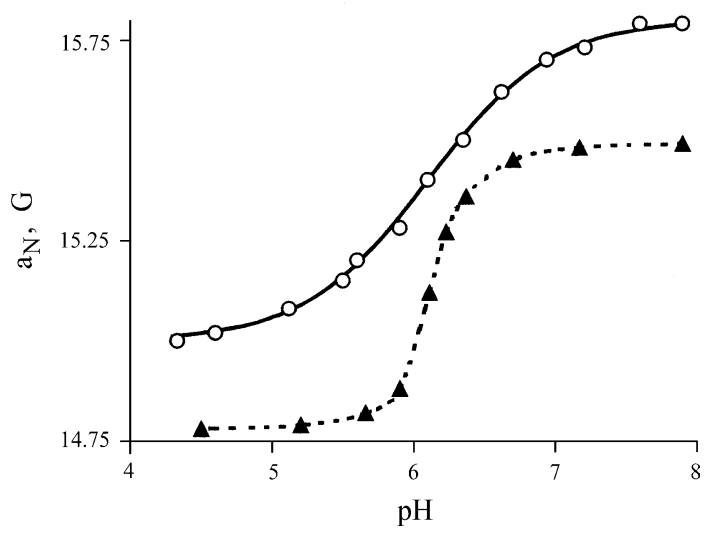

Figure 3. The $\mathrm{pH}$ dependence of hyperfine splitting, $a_{\mathrm{N}}$, measured as a distance between low- and central-field components of X-band (o) and L-band ( $\mathbf{\Lambda})$ EPR spectra. The solid line was calculated using Eq. (1) with parameters $a_{\mathrm{N}}(\mathrm{R})=15.8 \mathrm{G}$, $a_{\mathrm{N}}\left(\mathrm{RH}^{+}\right)=15.0 \mathrm{G}, \mathrm{pK}=6.1$.

The latter parameter, measured at X-band, or hyperfine splitting between low- and high-field components, measured at L-band (Fig. 2b) and referred as $2 a_{\mathrm{N}}$, have been used almost exclusively as highly sensitive $\mathrm{pH}$ markers in numerous applications [5,34-41]. However, the sensitivity of this parameter to pH strongly depends both on EPR frequency and spectrometer settings (e.g., modulation amplitude) and has to be studied for its optimal application. Figure 3 demonstrates the dependence of $a_{\mathrm{N}}$ on pH for the radical R2 measured from X-band and L-band EPR spectra. The observed narrowing of the $a_{\mathrm{N}}$ titration curve at L-band results, in its turn, in a narrower $\mathrm{pH}$ range being available for $\mathrm{pH}$ assessment using this parameter by L-band EPR. Therefore further we discuss the origin of this effect and the possibility of its correction.

As demonstrated in Fig. 3 for the radical R2, an $a_{\mathrm{N}}$ titration curve at X-band allows very good approximation by the equation:

$$
a_{\mathrm{N}}\left(\mathrm{H}^{+}\right)=\frac{a_{\mathrm{N}}(\mathrm{R})+a_{\mathrm{N}}\left(\mathrm{RH}^{+}\right) \times\left[\mathrm{H}^{+}\right] / K_{\mathrm{a}}}{1+\left[\mathrm{H}^{+}\right] / K_{\mathrm{a}}} .
$$

This is the conventional titration dependence for the case of fast frequency exchange between the $\mathrm{R}$ and $\mathrm{RH}^{+}$forms in terms of the EPR time scale. However, the imidazoline and imidazolidine spin $\mathrm{pH}$ probes normally demonstrate slow frequency $\mathrm{R}-\mathrm{RH}^{+}$exchange (Figs 1,2) in the $\mathrm{pH}$ range from 3 to 11 [42]. A good approximation of the titration curve for $a_{\mathrm{N}}$ measured as the distance between low- and centralfield components of the X-band spectra (Fig. 3) is accidental due to the following factors: (i) practically equal broadening of these two EPR lines due to superposition of $\mathrm{R}$ and $\mathrm{RH}^{+}$forms (see Fig. 2 and captions), and (ii) insignificant shift between $\mathrm{R}$ and $\mathrm{RH}^{+}$forms compared with the linewidths. In the case of the L-band EPR spectrum (Fig. 2b) the shift between these two forms of the radical at lowand high-field components is equal to the $\Delta a_{\mathrm{N}}$ value and becomes comparable with the linewidth. This results in significant disturbance of the EPR lineshape and in narrowing of the $a_{\mathrm{N}}$ titration curve (Fig. 3). Interestingly, broadening of the EPR linewidth by L-band spectra with detection at high modulation amplitude (Fig. 3c) increases the range of $\mathrm{pH}$ sensitivity of hf splitting (Fig. 4). Moreover, the detection at higher modulation amplitude results in significant improvement of signal-to-noise ratio. The described experimental approach could be important for applications in vivo where fundamental sensitivity is much lower. 


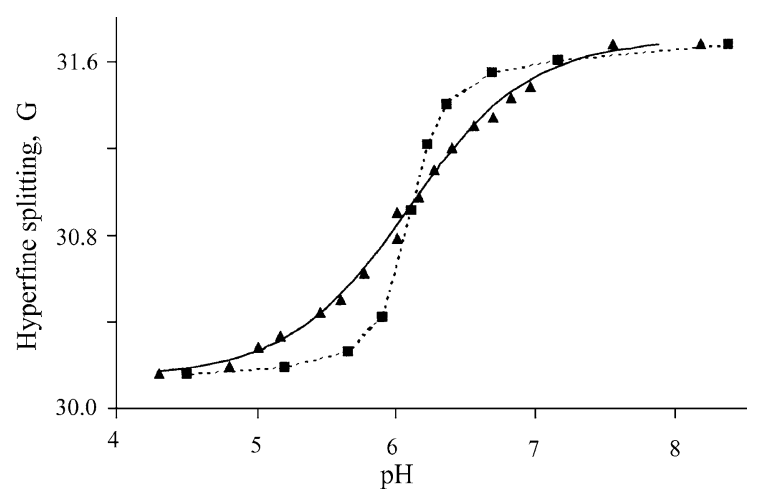

Figure 4. The $\mathrm{pH}$ dependences of hyperfine splitting, $2 a_{\mathrm{N}}$, measured as the distance between the low- and high-field components of the L-band EPR spectra detected at different modulation amplitude: $0.5 \mathrm{G}(\boldsymbol{\square})$ and $2 \mathrm{G}(\boldsymbol{\Lambda})$. The solid line was calculated using Eq. (1) with parameters $2 a_{\mathrm{N}}(\mathrm{R})=31.7 \mathrm{G}, 2 a_{\mathrm{N}}\left(\mathrm{RH}^{+}\right)=30.15 \mathrm{G}, \mathrm{pK}=6.1$.
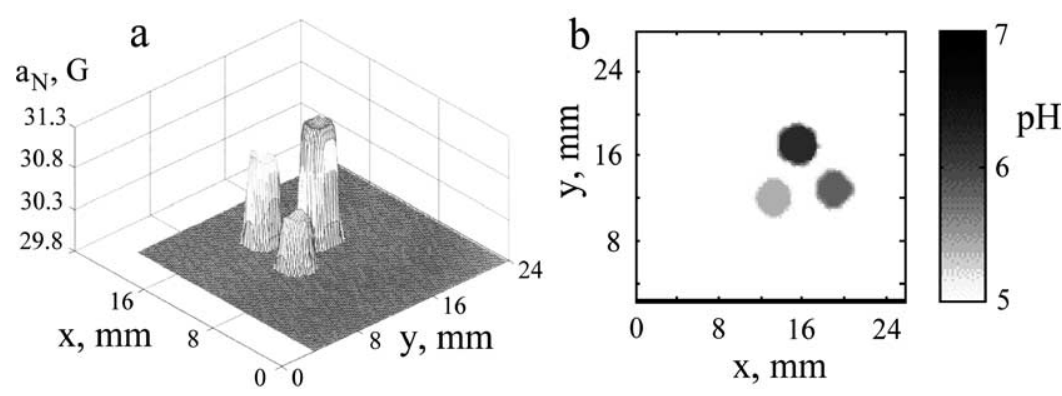

Figure 5. Cross-sectional 3D (1-spectral/2-spatial) image of a phantom prepared using capillary tubes of $2 \mathrm{~mm}$ diameter filled with $1 \mathrm{mM}$ solutions of the radical R2 prepared at different $\mathrm{pH}$. Left: spatial distribution of the hyperfine interaction splitting, $2 a_{\mathrm{N}}$, determined from position mapping of the low-field EPR peak. Right: $\mathrm{pH}$ map. The data acquisition parameters were: acquisition time, 5 min; projections, 64; maximum gradient, $30 \mathrm{G} / \mathrm{cm}$; field of view, $24 \mathrm{~mm}$.

\subsection{Imaging of $p H$-sensitive probes and $\mathrm{pH}$ mapping}

We have applied L-band EPR spectra detection at high modulation amplitude for developing of L-band $\mathrm{pH}$-mapping approach. The smooth $\mathrm{pH}$ dependence of the positions of the low- and high-field components enabled us to convert the 'position' image to 'pH map' after measuring the position of the low-field peak using spectral-spatial imaging. Figure 5 demonstrates the ability of the approach to map $\mathrm{pH}$ in the phantom sample. This approach shows good spatial $(0.2 \mathrm{~mm})$ and functional $(0.2 \mathrm{pH}$ units at $\mathrm{pH}$ close to $\mathrm{pK}$ of the radical) resolution and has potential for in vivo applications.

Proton electron double-resonance imaging (PEDRI) represents a different approach for imaging of the radicals. Recently we applied the field-cycled PEDRI approach to image spin $\mathrm{pH}$ probes in living rats and its spectroscopy analog, field-cycled dynamic nuclear polarization (FC-DNP), for $\mathrm{pH}$ measurements in the rat stomach $[8,34]$. The sensitivity of the approach can be improved using isotopically substituted $\mathrm{pH}$ sensitive nitroxides [27] which is important for increasing the experimental time window and lowering probe dosage. Both FC-PEDRI and FC-DNP use the Overhauser effect for detection of radicals. EPR irradiation of the radical's causes a transfer of polarization from electron to coupled proton spins, and the efficiency of this transfer depends, among other parameters, on the extent to which the EPR is saturated. At a given EPR irradiation power level (usually constrained by the requirement not to overheat the 


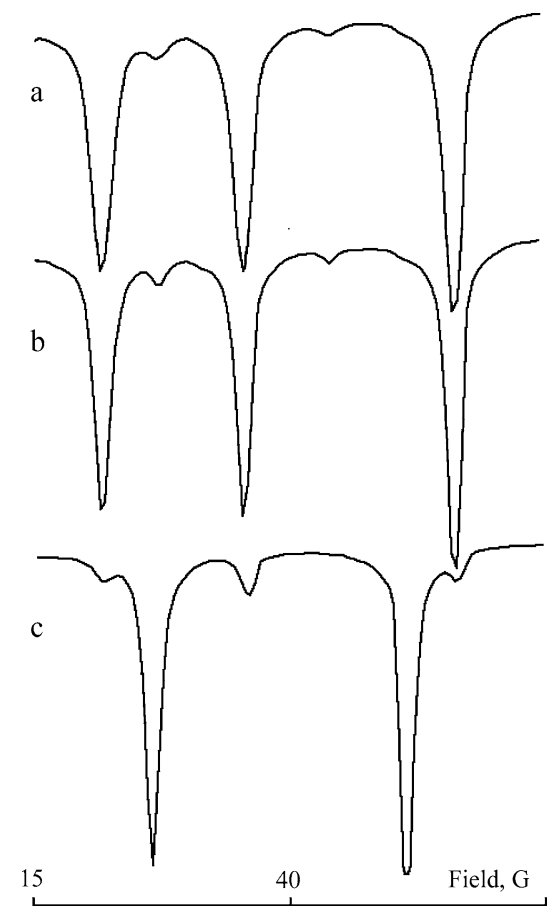

Figure 6. FC-DNP spectra recorded from $2 \mathrm{mM}$ aqueous solutions of R1 (a), R1* (b) and R1** (c). The pH values of the samples were $6.47,6.20$ and 6.25 , respectively (i.e., all above the $\mathrm{pK}$ of this agent), the volume $15 \mathrm{ml}$. The pulse sequence repetition time was $1200 \mathrm{~ms}$, with EPR irradiation at $121.04 \mathrm{MHz}$, applied power $19.5 \mathrm{~W}$ and duration $400 \mathrm{~ms}$.

animal under study) a narrow-line probe will be more saturated than its broader-line counterpart, so that the signal-to-noise ratio of the measured image or spectrum will be enhanced. Therefore, D-substituted agents, e.g., R1* (Scheme 2), are beneficial for these studies. A further benefit can be obtained from the use of ${ }^{15} \mathrm{~N}$-substituted agents (R1**, R2**, Scheme 2), since the reduction of the number of EPR lines from 3 to 2 again improves the efficiency of the Overhauser polarization transfer. Figure 6 shows typical FC-DNP spectra obtained from aqueous solutions of $\mathrm{R} 1, \mathrm{R} 1^{*}$ and $\mathrm{R} 1^{* *}$. It can be seen that the depth of the spectral lines is increased in the D-substituted agent and again by ${ }^{15} \mathrm{~N}$ substitution. Figure 7 shows a set of in vivo FC-PEDRI images obtained following gavage of $3 \mathrm{ml}$ of $5 \mathrm{mM} \mathrm{R} 2 * *$ solution into the animal's stomach. In the 'Difference' image (Fig. 7c) the location of the agent in the animal's stomach can clearly be seen.

Note that EPR spectra of the nitroxides with ${ }^{14} \mathrm{~N}-\mathrm{O}$ and ${ }^{15} \mathrm{~N}-\mathrm{O}$ fragments do not overlap (Fig. 8). This opens the principal possibility to distinguish the signals from different areas in heterogeneous samples, e.g., simultaneous detection of intracellular and extracellular $\mathrm{pH}$ with specifically targeted probes. Recently we proposed synthesis of $\mathrm{pH}$-sensitive nitroxides with ester groups for its intracellular targeting [43].

\subsection{Thiol sensitive nitroxyl biradicals of the imidazoline and imidazolidine types}

Imidazoline and imidazolidine biradical disulfides, $\mathrm{R}_{1} \mathrm{SSR}_{1}$ and $\mathrm{R}_{2} \mathrm{SSR}_{2}$ (Scheme 3 ) were earlier proposed as thiol-specific paramagnetic reagents $[24,25]$. These paramagnetic disulfides react with thiols with splitting of the disulfide bond, resulting in characteristic changes of the X-band EPR spectra 

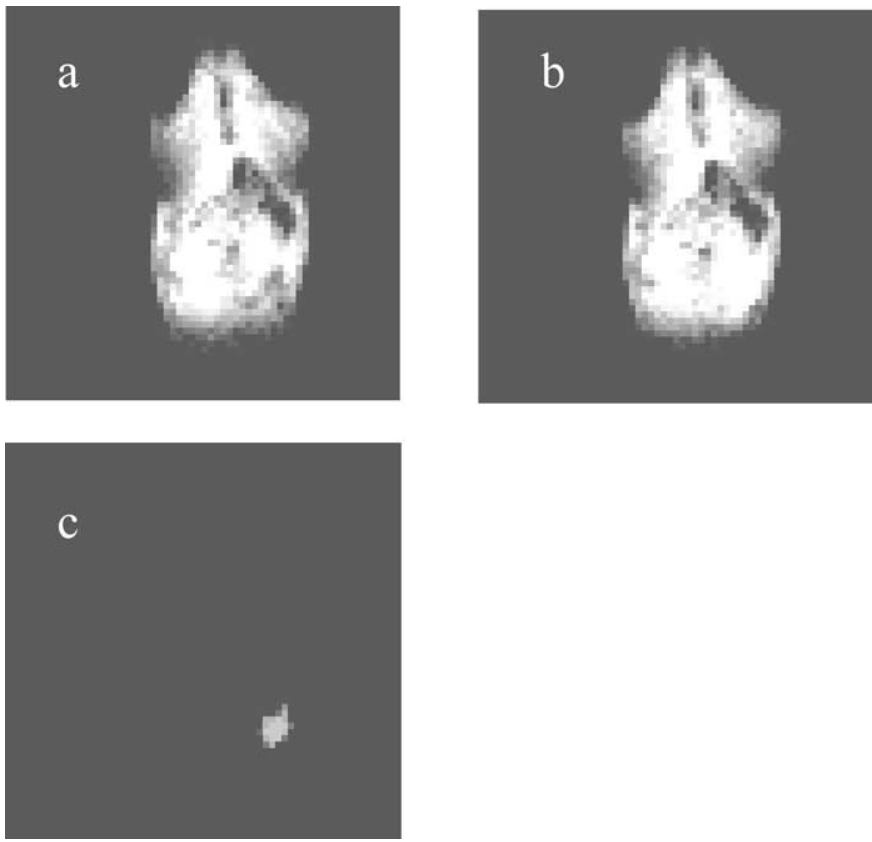

Figure 7. FC-PEDRI images obtained in vivo from an anesthetized Sprague-Dawley rat given a gavage of $3 \mathrm{ml}$ of $5 \mathrm{mM}$ solution of $\mathrm{R} 1{ }^{* *}$. The animal was imaged supine. Images are coronal projective (i.e., no slice selection) with field-of-view $150 \mathrm{~mm}$, matrix size $64 \times 64$. An interleaved (EPR off / EPR on) pulse sequence was used, with a repetition time (TR) of $1200 \mathrm{~ms}$. EPR irradiation was applied at $120 \mathrm{MHz}$, power $30 \mathrm{~W}$, duration $400 \mathrm{~ms}$, at field strength $5.25 \mathrm{mT}$. Images shown are EPR-off (a), EPR-on (b) and difference (c); the latter shows the location of the agent in the animal's stomach.

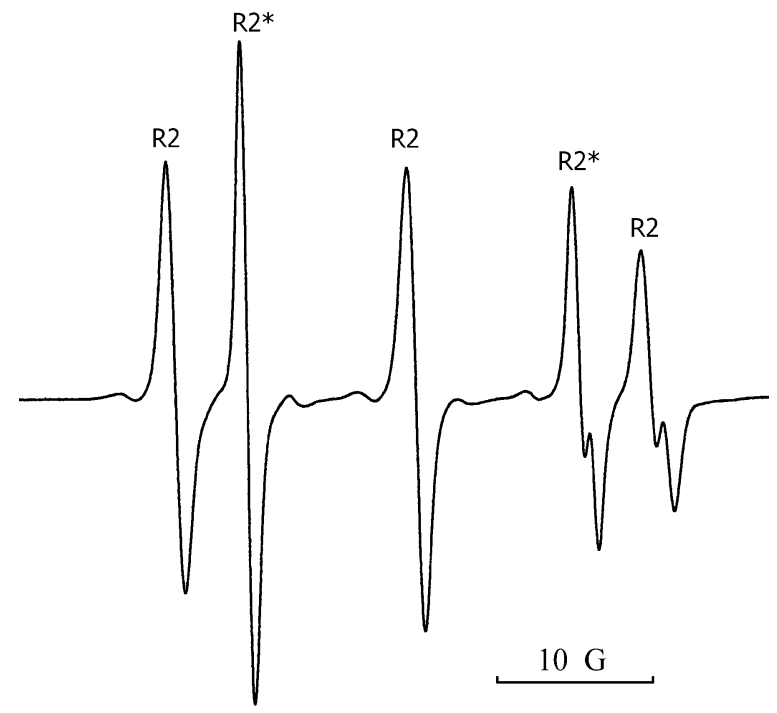

Figure 8. X-band EPR spectrum of the mixture of $0.5 \mathrm{mM}$ solutions of the radicals R2 and R2* in $0.1 \mathrm{mM}$ Na-phosphate buffer, $\mathrm{pH}$ 5.9. Spectrometer settings were as following: microwave power $10 \mathrm{~mW}$, modulation amplitude $0.8 \mathrm{G}$. 
(Fig. 9). The rate of the reaction of the biradicals with thiols increases with $\mathrm{pH}$. For the biradical $\mathrm{R}_{2} \mathrm{SSR}_{2}$ this reaction with $1 \mathrm{mM} \mathrm{GSH}$ proceeds in a few seconds at alkaline $\mathrm{pH}$ (Fig. 9). However at physiological $\mathrm{pH}$ the biradical $\mathrm{R}_{2} \mathrm{SSR}_{2}$ reacts with thiols slowly $\left(k \approx 0.26 \mathrm{M}^{-1} \mathrm{~s}^{-1}\right.$ for GSH at $\mathrm{pH} 7.0$ [25]) allowing the detection of the kinetics of the reaction (Fig. 10). The measurement of the kinetics of the biradical disulfide bond splitting does not require an excess of the label over thiols and therefore provides noninvasive experimental tool for thiols detection by EPR. Note that the fast reactive $\mathrm{R}_{1} \mathrm{SSR}_{1}$ probe can be applied only in a "static" approach which measures the fraction of the biradical splitted by the reaction

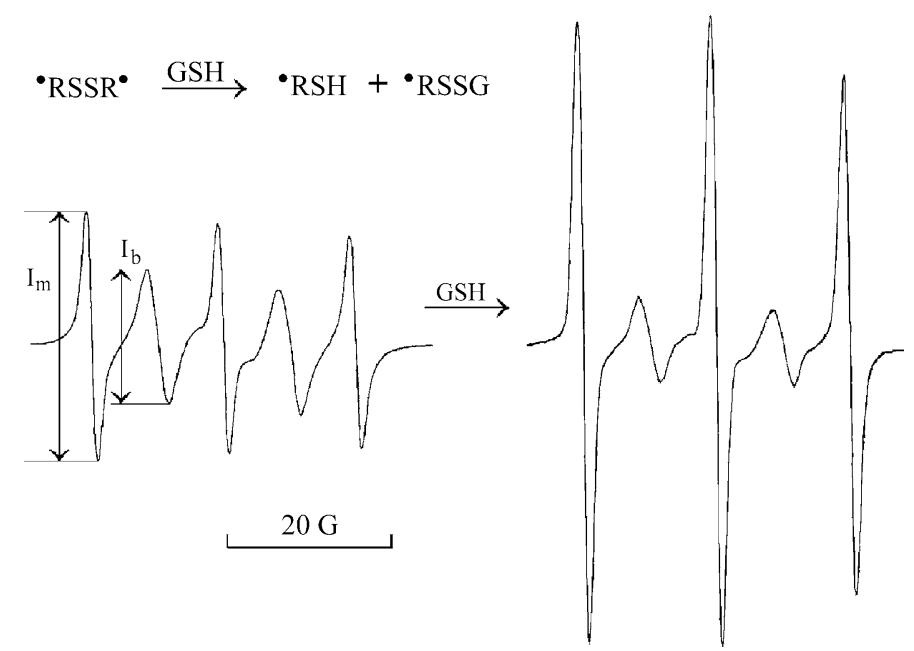

Figure 9. X-band EPR spectrum of $0.1 \mathrm{mM}$ solution of the $\mathrm{R}_{2} \mathrm{~S}-\mathrm{SR}_{2}$ in $10 \mathrm{mM} \mathrm{Na} 2 \mathrm{~B}_{4} \mathrm{O}_{7}$ buffer, pH 11.2, before (left) and $2 \mathrm{~min}$ after addition of $30 \mu \mathrm{M}$ GSH (right). Insert: the scheme of the reaction of thiol-disulfide exchange responsible for observed spectral changes. The measurement of relative changes of the intensities of monoradical (Im) or biradical (Ib) components allows quantitative determination of glutathione, GSH.

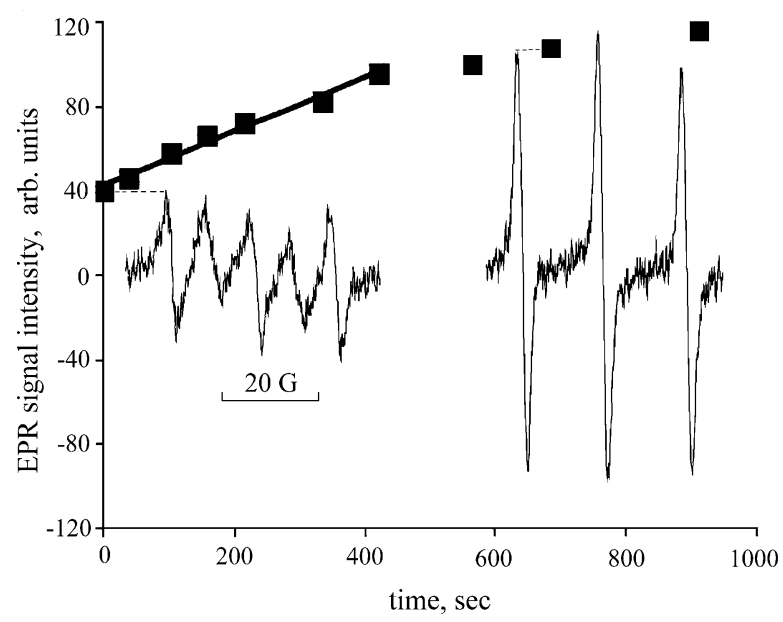

Figure 10. The kinetics of the increase of the low-field component of the L-band EPR spectra of the biradical $\mathrm{R}_{2} \mathrm{SSR}_{2}$ measured in the blood taken from the Sprague-Dawley rat. The linear approximation in the time range less than $400 \mathrm{sec}$ has been used for estimation of GSH concentration. Insert: L-band EPR spectra of the $100 \mu \mathrm{l}$ blood sample measured immediately (a) and $700 \mathrm{sec}$ (b) after addition of $5 \mu \mathrm{l}$ of the biradical $\mathrm{R}_{2} \mathrm{SSR}_{2}$, final concentration of the label $50 \mu \mathrm{M}$, acquisition time $10.5 \mathrm{~s}$. 
with thiols. This approach unambiguously requires an excess of the probe over thiols and results in total thiols consumption under measurement therefore making it impossible for in vivo use.

Figure 10 shows the time evolution of the L-band EPR spectra of the biradical $\mathrm{R}_{2} \mathrm{SSR}_{2}$ in untreated rat blood. The kinetics demonstrates a convenient time window for the biradical, $\mathrm{R}_{2} \mathrm{~S}-\mathrm{SR}_{2}$ reaction with thiols (mostly GSH), as well as its relative stability towards reduction (less than $10 \%$ of the radical was reduced during 15 min incubation in the blood). The $\mathrm{R}_{2} \mathrm{~S}_{-} \mathrm{SR}_{2}$ radical freely penetrates cellular membranes (lipophilicity coefficient $k=240$ [25]) reacting preferably with GSH located in erythrocytes. The reaction with protein thiols seems to be very slow: the rates constants for the reaction of $\mathrm{R}_{2} \mathrm{~S}-\mathrm{SR}_{2}$ with SH groups of human serum albumin and hemoglobin are hundreds of times less compared with that for GSH [25]. This allows an estimate of the reduced GSH concentration in the whole rat blood from the linear part of the kinetics shown in Fig. 10, which was found to be equal to $0.95 \pm 0.2 \mathrm{mM}$, in reasonable agreement with literature data $[44,45]$.

Recently we demonstrated the possibility of applying the kinetic EPR approach, using a redoxsensitive nitroxide, for GSH mapping in vivo in tumor-bearing mice [2]. However it is necessary to note that the applied probe was not GSH- or thiol-specific, but rather sensitive to any reducing compound. Therefore application of SH-sensitive probe, $\mathrm{R}_{2} \mathrm{SSR}_{2}$, which entails a similar kinetic EPR approach, might provide even more specific information and approach for GSH mapping.

In summary, $\mathrm{pH}$ and $\mathrm{SH}$ sensitive imidazoline and imidazolidine nitroxides were found to be the promising functional probes for biological EPR applications, including that in vivo.

\section{Acknowledgements}

The authors thank Dr. Yuanmu Deng and Valerie Wright for technical assistance. This work was partly supported by grants from The Royal Society (London), INTAS (No. 99-1086), NHLB 53333, and CA78886.

\section{References}

[1] L.J. Berliner and H. Fujii, Magnetic resonance imaging of biological specimens by electron paramagnetic resonance of nitroxide spin labels, Science 227 (1985), 517-519.

[2] P. Kuppusamy, H. Li, G. Ilangovan, A.J. Cardounel, J.L. Zweier, K. Yamada, M.C. Krishna and J.B. Mitchell, Noninvasive imaging of tumor redox status and its modification by tissue glutathione levels, Cancer Res. 62 (2002), 307-312.

[3] H. Fujii and L.J. Berliner, In vivo EPR evidence for free radical adducts of nifedipine, Magn. Reson. Med. 42 (1999), 691-694.

[4] N. Khan and H. Swartz, Measurements in vivo of parameters pertinent to ROS/RNS using EPR spectroscopy, Mol. Cell Biochem. 234-235 (2002), 341-357.

[5] A. Sotgiu, K. Mäder, G. Placidi, S. Colacicchi, C.L. Ursini and M. Alecci, pH-sensitive imaging by low-frequency EPR: a model study for biological applications, Phys. Med. Biol. 43 (1998), 1921-1930.

[6] P. Gallo, S. Colacicchi, M. Ferrari, G. Gualtieri and A. Sotgiu, Electron paramagnetic resonance spectroscopy on isolated rat heart: a technical note, Cardioscience 2 (1991), 221-224.

[7] D.J. Lurie, Free radical imaging, Br. J. Radiol. 74 (2001), 782-784.

[8] V.V. Khramtsov, I.A. Grigor'ev, M.A. Foster, D.J. Lurie and I. Nicholson, Biological applications of spin pH probes, Cell. Mol. Biol. 46 (2000), 1361-1374.

[9] I. Nicholson, F.J. Robb, S.J. McCallum, A. Koptioug and D.J. Lurie, Recent developments in combining LODESR imaging with proton NMR imaging, Phys. Med. Biol. 43 (1998), 1851-1855.

[10] D.J. Lurie, H. Li, S. Petryakov and J.L. Zweier, Development of a PEDRI free-radical imager using a 0.38 T clinical MRI system, Magn. Reson. Med. 47 (2002), 181-186.

[11] D.J. Lurie, M.A. Foster, D. Yeung and J.M. Hutchison, Design, construction and use of a large-sample field-cycled PEDRI imager, Phys. Med. Biol. 43 (1998), 1877-1886. 
[12] V.V. Khramtsov, New approaches in spin labeling and spin trapping. Part one: ESR studies of local chemical environment, in: Supramolecular Structure and Function 7, G. Pifat-Mrzljak, ed., Kluwer Academic/Plenum Publishers, New York, Boston, Dordrecht, London, Moscow, 2001, pp. 89-105.

[13] J.I. Vandenberg, J.C. Metcalfe and A. Grace, Mechanisms of pHi recovery after global ischemia in the perfused heart, Circ. Res. 72 (1993), 993-1003.

[14] G. Helmlinger, F. Yuan, M. Dellian and R.K. Jain, Interstitial pH and pO2 gradients in solid tumors in vivo: high-resolution measurements reveal a lack of correlation, Nat. Med. 3 (1997), 177-182.

[15] M. Thangaraju, K. Sharma, B. Leber, D.W. Andrews, S.H. Shen and C.B. Srikant, Regulation of acidification and apoptosis by SHP-1 and Bcl-2, J. Biol. Chem. 274 (1999), 29549-29557.

[16] G. Ilangovan, H. Li, J.L. Zweier and P. Kuppusamy, In vivo measurement of tumor redox environment using EPR spectroscopy, Mol. Cell. Biochem. 234-235 (2002), 393-398.

[17] U. Issberner, P.W. Reeh and K.H. Steen, Pain due to tissue acidosis: a mechanism for inflammatory and ischemic myalgia?, Neurosci. Lett. 208 (1996), 191-194.

[18] S. Pietri, S. Martel, M. Culcasi, M.-C. Delmas-Beauvieux, P. Canioni and J.-L. Gallis, Use of diethyl(2-methylpyrrolidin2-yl)phosphonate as a highly sensitive extra- and intracellular 31P NMR pH indicators in isolated organs, J. Biol. Chem. 276 (2001), 1750-1758.

[19] R.J. Gillies, J.R. Alger, J.A. den Holander and R.G. Shulman, Intracellular pH measured by NMR: methods and results, in: Intracellular pH: Its Measurement, Regulation and Utilization in Cellular Functions, R. Nuccitelli and D.W. Deamer, eds, Alan R. Liss, New York, 1982, pp. 79-104.

[20] B.S. Szwergold, NMR spectroscopy of cells, Annu. Rev. Physiol. 54 (1992), 775-798.

[21] P. Lundberg, E. Harmsen, C. Ho and H.J. Vogel, Nuclear magnetic resonance studies of cellular metabolism, Anal. Biochem. 191 (1990), 193-222.

[22] J.F.W. Keana, M.J. Acarregui and S.L.M. Boyle, 2,2-disubstituted-4,4-dimethylimidazolidinyl-3-oxy nitroxides indicators of aqueous acidity through variation of $a_{\mathrm{N}}$ with $\mathrm{pH}, J$. Am. Chem. Soc. 104 (1982), 827-830.

[23] V.V. Khramtsov, L.M. Weiner, I.A. Grigor'ev and L.B. Volodarsky, Proton exchange in stable nitroxyl radicals. EPR study of the $\mathrm{pH}$ of aqueous solutions, Chem. Phys. Lett. 91 (1982), 69-72.

[24] V.V. Khramtsov, V.I. Yelinova, L.M. Weiner, T.A. Berezina, V.V. Martin and L.B. Volodarsky, Quantitative determination of SH groups in low- and high-molecular weight compounds by an ESR method, Anal. Biochem. 182 (1989), 58-63.

[25] V.V. Khramtsov, V.I. Yelinova, Yu.I. Glazachev, V.A. Reznikov and G. Zimmer, Quantitative determination and reversible modification of thiols using imidazolidine biradical disulfide label, J. Biochem. Biophys. Methods 35 (1997), 115-128.

[26] L.B. Volodarsky, V.A. Reznikov and I.A. Grigor'ev, Chemical properties of heterocyclic nitroxides, in: Imidazoline Nitroxides, L.B.Volodarsky, ed., Boca Raton, 1988, pp. 29-76.

[27] Yu.I. Glazachev, I.A. Grigor'ev, E.J. Reijerse and V.V. Khramtsov, EPR studies of 15N- and 2H-substituted pH-sensitive spin probes of imidazoline and imidazolidine types, Appl. Magn. Reson. 20 (2001), 489-505.

[28] J.L. Zweier and P. Kuppusamy, Electron paramagnetic resonance measurements of free radicals in the intact beating heart: a technique for detection and characterization of free radicals in whole biological tissues, Proc. Natl. Acad. Sci. USA $\mathbf{8 5}$ (1988), 5703-5707.

[29] P. Kuppusamy, M. Chzhan, A. Samouilov, P. Wang and J.L. Zweier, Mapping the spin-density and lineshape distribution of free radicals using 4D spectral-spatial EPR imaging, J. Magn. Reson. B 107 (1995), 116-125.

[30] P. Kuppusamy, M. Chzhan and J.L. Zweier, Development and optimization of three-dimensional spatial EPR imaging for biological organs and tissues, J. Magn. Reson. B 106 (1995), 122-130.

[31] P. Kuppusamy, M. Chzhan, K. Vij, M. Shteynbuk, D.J. Lefer, E. Giannella and J.L. Zweier, Three-dimensional spectralspatial EPR imaging of free radicals in the heart: a technique for imaging tissue metabolism and oxygenation, Proc. Natl. Acad. Sci. USA 91 (1994), 3388-3392.

[32] R.K. Woods, W.B. Hyslop, M.R.B. and P.C. Lauterbur, Image reconstruction, in: EPR Imaging and in vivo EPR, G.R. Eaton, S.S. Eaton and K. Ohno, eds, CRC Press, Boca Raton, 1991, pp. 91-117.

[33] V.V. Khramtsov, L.M. Weiner, S.I. Eremenko, O.I. Belchenko, P.V. Schastnev, I.A. Grigor'ev and V.A. Reznikov, Proton exchange in stable nitroxyl radicals of imidazoline and imidazolidine series, J. Magn. Reson. 61 (1985), 397-408.

[34] M.A. Foster, I.A. Grigor'ev, D.J. Lurie, V.V. Khramtsov, S. McCallum, I. Panagiotelis, J.M.S. Hutchison, A. Koptioug and I. Nicholson, In vivo detection of a $\mathrm{pH}$-sensitive nitroxide in the rat stomach by low-field ESR-based techniques, Magn. Reson. Med. 49 (2003), 558-567.

[35] K. Mäder, B. Gallez, K.J. Liu and H.M. Swartz, Non-invasive in vivo characterization of release processes in biodegradable polymers by low-frequency electron paramagnetic resonance spectroscopy, Biomaterials 17 (1996), $457-461$.

[36] B. Gallez, K. Mäder and H.M. Swartz, Noninvasive measurement of the pH inside the gut by using pH-sensitive nitroxides: An in vivo EPR study, Magn. Reson. Med. 36 (1996), 694-697.

[37] C. Kroll, W. Hermann, R. Stosser, H.H. Borchert and K. Mäder, Influence of drug treatment on the microacidity in rat and human skin - an in vitro electron spin resonance imaging study, Pharm. Res. 18 (2001), 525-530. 
[38] A. Brunner, K. Mäder and A. Gopferich, $\mathrm{pH}$ and osmotic pressure inside biodegradable microspheres during erosion, Pharm. Res. 16 (1999), 847-853.

[39] K. Mäder, B. Bittner, Y. Li, W. Wohlauf and T. Kissel, Monitoring microviscosity and microacidity of the albumin microenvironment inside degrading microparticles from poly(lactide-co-glycolide) (PLG) or ABA-triblock polymers containing hydrophobic poly(lactide-co-glycolide) A blocks and hydrophilic poly(ethyleneoxide) B blocks, Pharm. Res. 15 (1998), 787-793.

[40] C. Kroll, K. Mäder, R. Stosser and H.H. Borchert, Direct and continuous determination of pH values in nontransparent w/o systems by means of EPR spectroscopy, Eur. J. Pharmaceut. Sci. 3 (1995), 21-26.

[41] K. Mäder, S. Nitschke, R. Stosser and H.-H. Borchert, Non destructive and localized assessment of acidic microenvironments inside biodegradable polyanhydrides by specral spatial electron paramagnetic resonance imaging, Polymer $\mathbf{3 8}$ (1997), 4785-4794.

[42] V.V. Khramtsov and L.B. Volodarsky, Use of imidazoline nitroxides in studies of chemical reactions: ESR measurements of concentration and reactivity of protons, thiols and nitric oxide, in: Biological Magnetic Resonance, Vol. 14: Spin Labeling: The Next Millennium, L.J. Berliner, ed., Plenum Press, New York and London, 1998, pp. 109-180.

[43] M. Voinov and I.A. Grigor'ev, in: 3rd International Conference on Nitroxide Radicals, Kaiserslautern, Germany, 2001, p.110.

[44] L. Hagenfeldt, A. Arvidsson and A. Larsson, Glutathione and -glutamylcysteine in whole blood, plasma and erythrocytes, Clin. Chim. Acta 85 (1978), 167-173.

[45] A.F. Boyne and G.L. Ellman, A methodology for analysis of tissue sulfhydryl components, Anal. Biochem. 46 (1972), 639-653. 


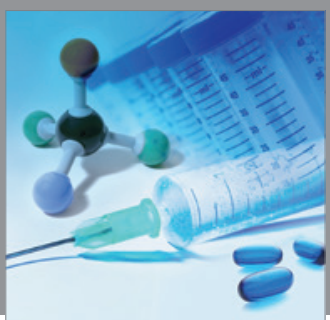

International Journal of

Medicinal Chemistry

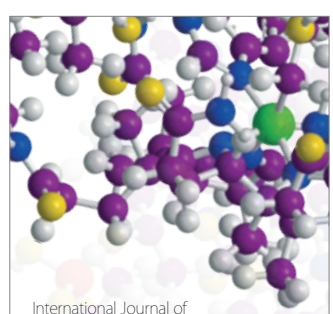

Carbohydrate Chemistry

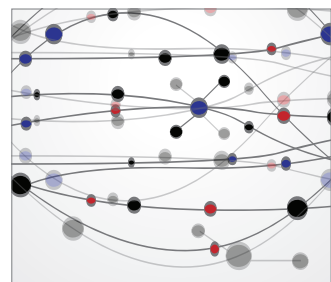

The Scientific World Journal
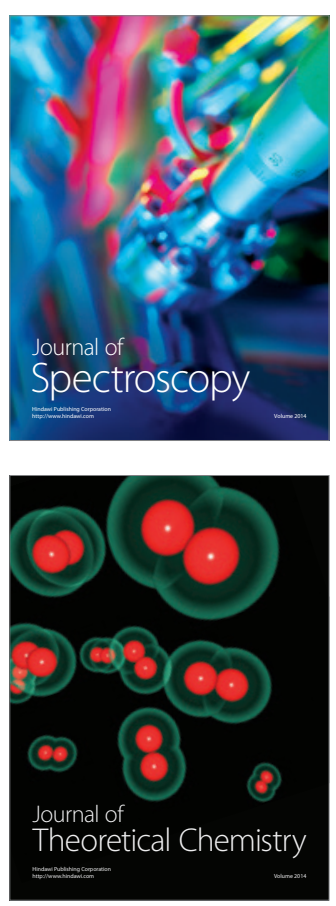
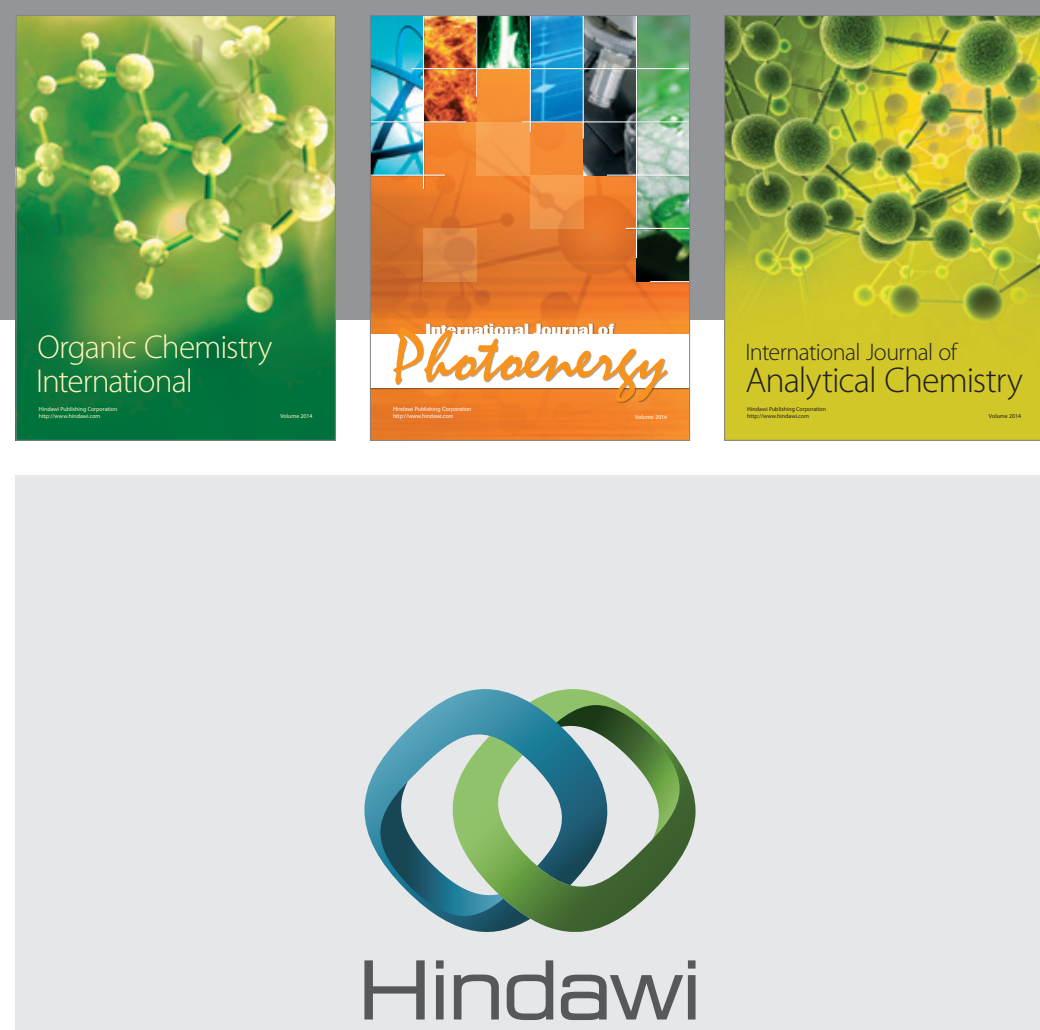

Submit your manuscripts at

http://www.hindawi.com
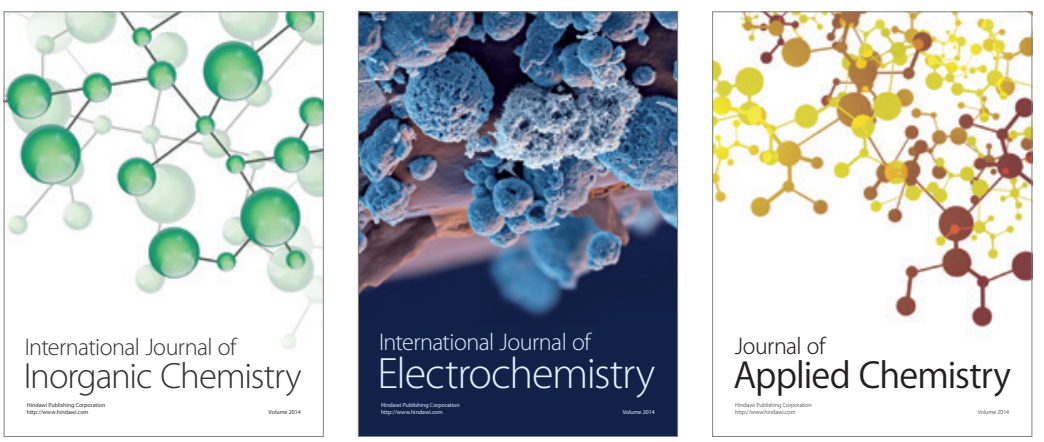

Journal of

Applied Chemistry
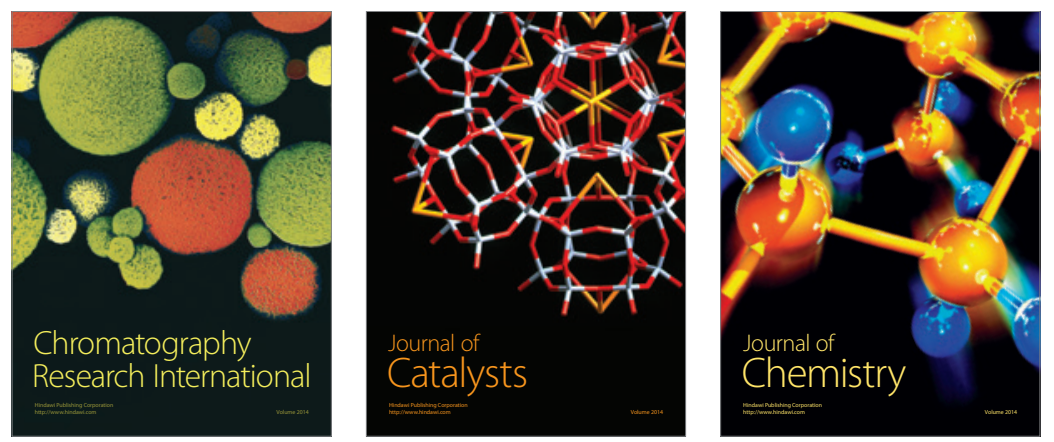
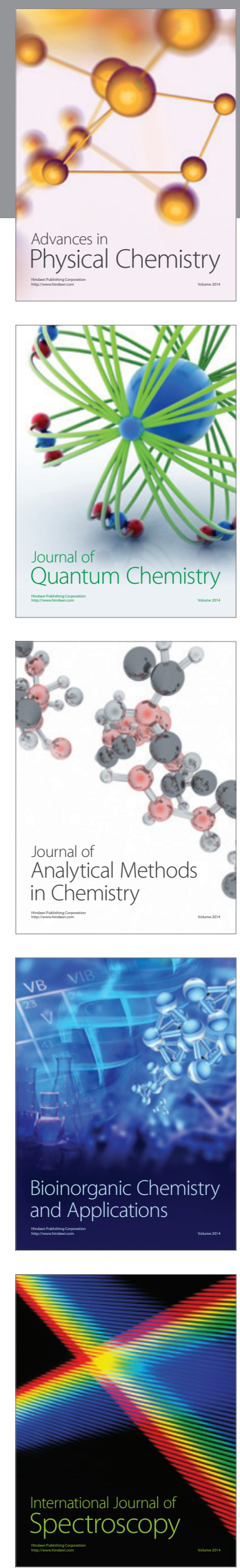